\title{
PERFORMANCE COMPARISON OF THREE DIFFERENT REACTORS (MBBR, MBR AND MBBMR) FOR MUNICIPAL WASTEWATER TREATMENT
}

Noman Sohail a, Sadia Ahmed ${ }^{\text {a }}$, Shinho Chung ${ }^{a^{*}}$, Muhammad Saqib Nawaz ${ }^{\text {b }}$

\author{
a. Forman Christian College (A Chartered University), Ferozepur road, Lahore, Pakistan \\ b. Water Desalination and Reuse Center, Division of Biological and Environmental Science and Engineering, \\ King Abdullah University of Sciences and Technology, Thuwal, 23955-6900, Sauid Arabia, Tel. +966 \\ 565854972; email: muhammad.nawaz.1@kaust.edu.sa \\ * Corresponding Author: Cell Phone 0092 3413258247; E-mail: shinhochung@fccollege.edu.pk \\ Email addresses of Authors: (nomansohail1122@yahoo.com; sadiajawad246@gmail.com) \\ Contact numbers of Authors: (Noman Sohail: 0092 3026683706; Sadia Ahmad: 0092 3317464888; Saqib Nawaz: \\ 00966565854972 )
}

\begin{abstract}
Membrane bioreactor (MBR) is an innovative wastewater treatment technology in which solid and liquid separation is done through membrane. Advantages of MBR technology involves better effluent quality, less foot print and less waste sludge generation. However, membrane biofouling is a major hindrance in the use of MBR that leads to clogging of membranes. Moving bed biofilm reactor (MBBR) encompasses use of carriers moving by aeration that provide surface to microorganism for attached growth. MBBR increases solid retention time (SRT), thus slowing down the growth rate of microorganisms. For better results, both technologies MBR and MBBR can be combined together to make moving bed biofilm membrane reactor (MBBMR), a hybrid technique which improves the removal efficiency, lessens sludge generation and minimizes biofouling. This study investigated the biofilm formation and influence of sponge and plastic suspended carriers in MBBR and MBBMR. This study compared removal efficiency of organic matter and ammonia, effluent production and operational duration as well as waste sludge generation. These results infer COD, BOD and $\mathrm{NH}^{+}{ }_{-}^{-} \mathrm{N}$ removal of all technologies above $90 \%, 95 \%$ and $98 \%$ respectively. Hybrid MBBMR with sponge carrier showed the best performance for its high effluent production, longer operational duration and less waste sludge generation as compared to the other technologies, which make it economically viable among other technologies.
\end{abstract}

Keywords: Membrane Bioreactor (MBR); Moving Bed Biofilm Reactor (MBBR); Moving Bed Biofilm Membrane Reactor (MBBMR); Performance evaluation; wastewater treatment

\section{INTRODUCTION}

MBR has been prioritized from last two decades over the conventional procedures due to its great advantages and efficiency [1]. Membranes replaces the clarifier in the wastewater treatment system. It can be operational at higher suspended biomass concentrations, resulting in long sludge retention times as well as low sludge production without problem of sludge bulking [2]. An advantage of MBR technology is that it is a single step process in which MLSS concentration is easily maintained between 8,000 to $12,000 \mathrm{mg} / \mathrm{L}$. 
However, activated sludge process (ASP) works between 2,000 to 3,000mg/L because greater MLSS concentration may cause settling problem in the sedimentation basin [3].

Another alternate to the ASP is the use of the moving bed biofilm reactor (MBBR) technology which was developed in 1980 in Norway [2]. In the new approach of treating wastewater, the MBBR corresponds to different variety of field. The operation of the MBBR is the same like activated sludge process having freely moving carrier by air [7]. The MBBR technology enriches biofilm attached on carriers which are freely moving in the reactor. These carriers are commonly made of plastic. As an outcome, MBBR gives positive aspects of both suspended and attached growth throughout the process because less biomass comes back from the clarifier tank [4]. Advantage of MBBR over ASP includes less footprint, less cleaning, and long solid retention time for slow growing microorganisms [5]. In MBBR technique, submerged biofilm carriers subsequently separate solid and liquid. As a result, there is reduction of organic compound such as COD, BOD etc. [6]. The attached growth media is an important input in the operation process. With the recent advancements, varieties of new media have been used e.g. plastic media (Kaldnes K1, K2, K3 and K5), wood chips, biodegradable polymer, activated carbon (AC), ceramic carriers, naturally occurring materials and polyvinyl alcohol gel carrier [8]. For the promotion of the attached biofilm growth, smooth cylinders, external fins and cylinders with internal crosses, rectangles and cubes are also employed [7].

For better results, both technologies MBR and MBBR can be combined together to make, so called, moving bed biofilm membrane reactor (MBBMR). Two different techniques can be utilized at the same time while operating the MBBMR process. Through this hybrid technique, the problems of the activated sludge processes and membrane fouling by high biomass concentrations can be reduced [9]. This hybrid technique may improve the removal efficiency and also enhance the process of nitrification and denitrification. The MBBMR may have many advantages over the MBR such as higher organic loading rates, less sludge production rate, better oxygen transfer and higher biological reaction rates through the accumulation of high concentrations of active biomass [10]. The MBBMR system diminishes the issues of fouling. It also deals with the settle-ability concerns. It is attractive for users because it can overcome space constraints and efficient quality can be met through it [7]. This study investigates biofilm formation in MBR and influence of sponge and plastic suspended carriers in MBBR and MBBMR to improve performance of wastewater treatment by comparison of three technologies (MBR, MBBR and MBBMR) in terms of effluent production, operational duration and sludge generation.

\section{MATERIALS AND METHODS}

\subsection{Wastewater}

Synthetic wastewater which simulates domestic wastewater was prepared in lab in which organic compound such as COD, BOD, phosphorus and ammonia were present. The synthetic wastewater contains several component such as, glucose $(120 \mathrm{mg} / \mathrm{L})$, Peptone $(90 \mathrm{mg} / \mathrm{L})$, Yeast extract $(12 \mathrm{mg} / \mathrm{L}),\left(\mathrm{NH}_{4}\right)_{2} \mathrm{SO}_{4}(96 \mathrm{mg} / \mathrm{L})$, $\mathrm{KH}_{2} \mathrm{PO}_{4}(17 \mathrm{mg} / \mathrm{L}), \mathrm{NaHCO}_{3}(300 \mathrm{mg} / \mathrm{L}), \mathrm{CaCl}_{2}(2.40 \mathrm{mg} / \mathrm{L}), \mathrm{MgSO}_{4} \cdot 7 \mathrm{H}_{2} \mathrm{O}(24 \mathrm{mg} / \mathrm{L}), \mathrm{MnSO}_{4} \cdot 5 \mathrm{H}_{2} \mathrm{O}$ $(2.16 \mathrm{mg} / \mathrm{L}), \mathrm{FeCl}_{3} \cdot 6 \mathrm{H}_{2} \mathrm{O}(0.12 \mathrm{mg} / \mathrm{L})[11]$.

\subsection{Attached Growth Media}


Two reactors were filled with $20 \%$ of Kaldnes1 (plastic carrier) and polyurethane foam (sponge carriers) separately as bulk volume of total volume of reactor as used in previous study [8]. Physical characteristics of the plastic carrier and sponge carrier and their photos are shown in Table 2.1 and Figure 2.1 respectively

Table 2.1 Physical Characteristics of Plastic and Sponge carriers

\begin{tabular}{|c|c|c|}
\hline Parameters & Plastic Carrier & Sponge Carrier \\
\hline Material & Polyethylene $(\mathrm{PE})$ & Polyurethane $(\mathrm{PU})$ \\
\hline Shape & $\begin{array}{c}\text { Cylindrical with external } \\
\text { fins and internal cross }\end{array}$ & Cubic \\
\hline Size & $\varphi 7 \mathrm{~mm}$ & $1 \mathrm{~cm} \times 1 \mathrm{~cm} \times 1 \mathrm{~cm}$ \\
\hline Average Weight & $140 \mathrm{mg}$ & $40 \mathrm{mg}$ \\
\hline Specific surface area & $5.0 \times 10^{-3}\left(\mathrm{~m}^{2} / \mathrm{g}\right)$ & - \\
\hline
\end{tabular}
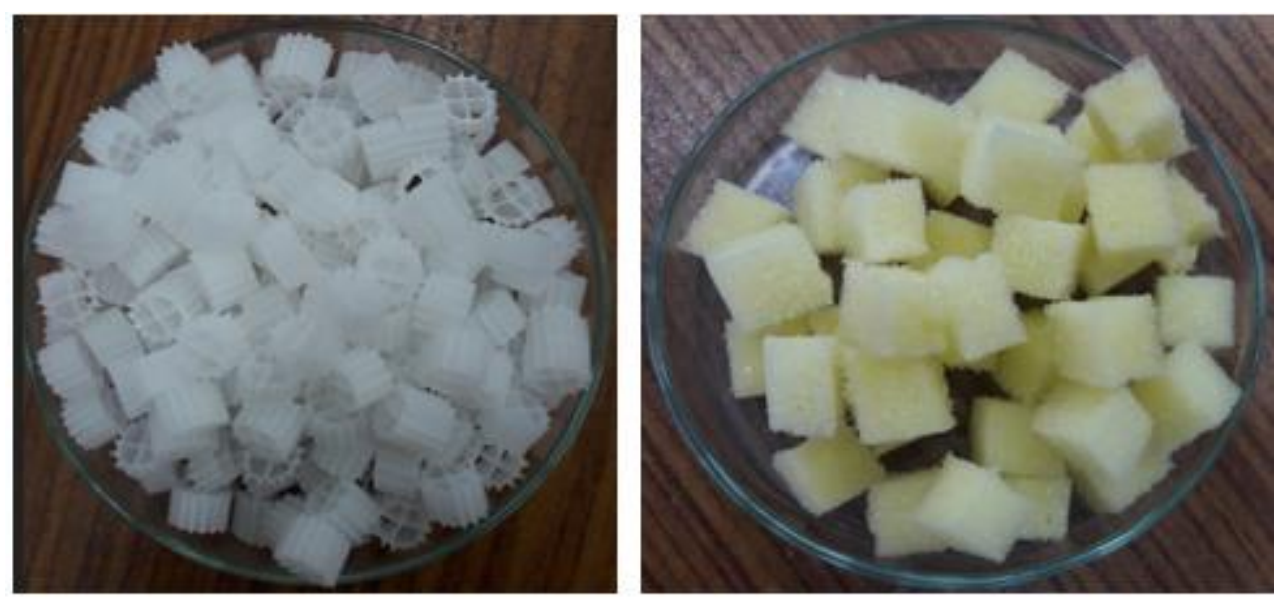

Figure 2.1 Plastic and Sponge carriers

\subsection{Membrane module}

The membrane module was prepared with hollow fiber poly-vinylidene difluoride (PVDF) membrane provided by PHILOS Korea. Specification of membrane module for this research and its photo are shown in Table 2.2 and Figure 2.2 respectively

Table 2.2 Specifications of Membrane Module

\begin{tabular}{|c|c|}
\hline Specification & Description \\
\hline Module design & Loop type \\
\hline Effective length/fiber & $50 \mathrm{~cm}=25 \mathrm{~cm} \mathrm{x} 2$ \\
\hline No. of module/reactor & 1 \\
\hline Surface area & $578.04 \mathrm{~cm}^{2} /$ module \\
\hline Flux & $27 \mathrm{LMH}$ \\
\hline
\end{tabular}




\begin{tabular}{|l|l|}
\hline Max TMP & 4.8 psi $(33 \mathrm{kpa})$ \\
\hline
\end{tabular}

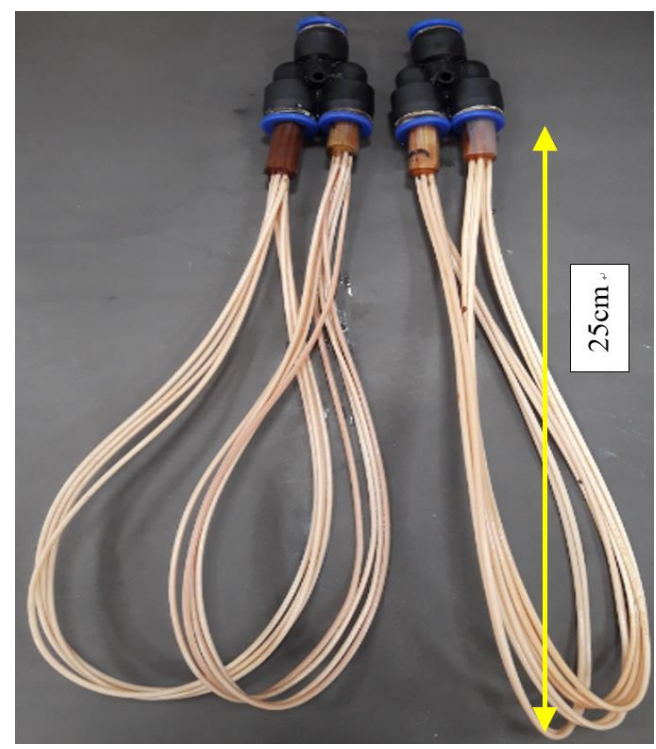

Figure 2.2 Membrane Module Used in MBR and MBBMR

\subsection{Reactor and Operational Setup}

Bioreactors made up of poly-acrylic plastic sheet were used in this study. Activated sludge process (ASP) was operated first as control group (no media in the reactor) as shown in Figure 2.3. And then MBBRs, MBR and MBBMRs were operated as research groups. Plastic carriers as attached growth media were added in the reactor to make MBBR1 and sponge carriers were added in the reactor to make MBBR2. These two reactors were operated in parallel. The size and operational condition were the same with those of ASP. For the membrane involving technologies, the same sized reactor was used for MBRs. No media, plastic and sponge carriers were added in each MBRs to make simple MBR, MBBMR1 and MBBMR2 respectively. The working volume of all reactors was $8 \mathrm{~L}$ each. At the top of the reactors floating valve was installed to maintain the level of mixed liquor in the reactor and synthetic wastewater was fed through gravity. Air diffusers were installed at the bottom of all reactors to provide oxygen to microorganisms and homogenized the mixed liquor. The aeration rate was set at $3 \mathrm{~L} / \mathrm{min}$. Peristaltic pumps (Longer Pump BT100-1L) were used for precise flow control of effluent, recycling sludge and backwash of membrane. Schematic diagrams of different treatment technologies are shown in Figure 2.3 and 2.4.

The hydraulic retention time (HRT) was kept at 10hr for ASP and MBBRs and 5hr for MBR and MBBMRs. Intentionally two times longer HRT was maintained for ASP and MBBRs than for membrane involving technologies (MBR and MBBMRs) to achieve the same effluent quality in all different operations. ASP was not able to treat wastewater well enough in HRT 5 8hr. Therefore extended HRT was applied for ASP and MBBRs. 100\% sludge return flowrate (compared to influent flowrate) was used and some of the sludge was wasted from the sedimentation basin in ASP and MBBRs to maintain proper amount of biomass in the bioreactor. In the membrane involving technologies, a set of 10min filtration and $1 \mathrm{~min}$ backwash was 
repeated. A part of mixed liquor was taken out from the bioreactor directly after checking mixed liquor suspended solids (MLSS) to maintain target MLSS concentration. Total six different operations were run to compare their performance. Simple MBR operation with backwash was run as one of research operation as well as control operation against two MBBMRs. Two hybrid MBBMRs were run as research operations that are expected to show better performance. MBBMRs had the same operational conditions with those of MBR except carriers in the bioreactor. MBBMR with plastic carriers was named as MBBMR1 and MBBMR with sponge carriers was named as MBBMR2. Operational conditions used in this research are summarized in Table 2.3.

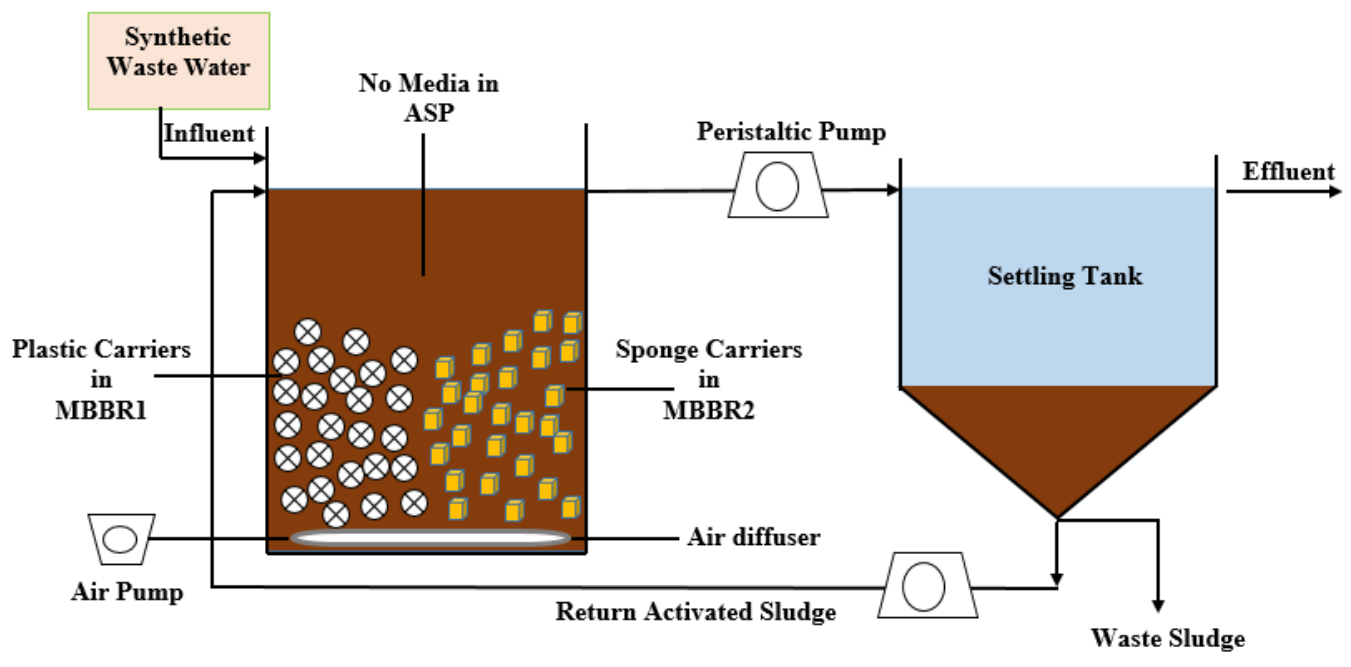

Figure 2.3 Schematic Diagram of ASP and MBBR plants

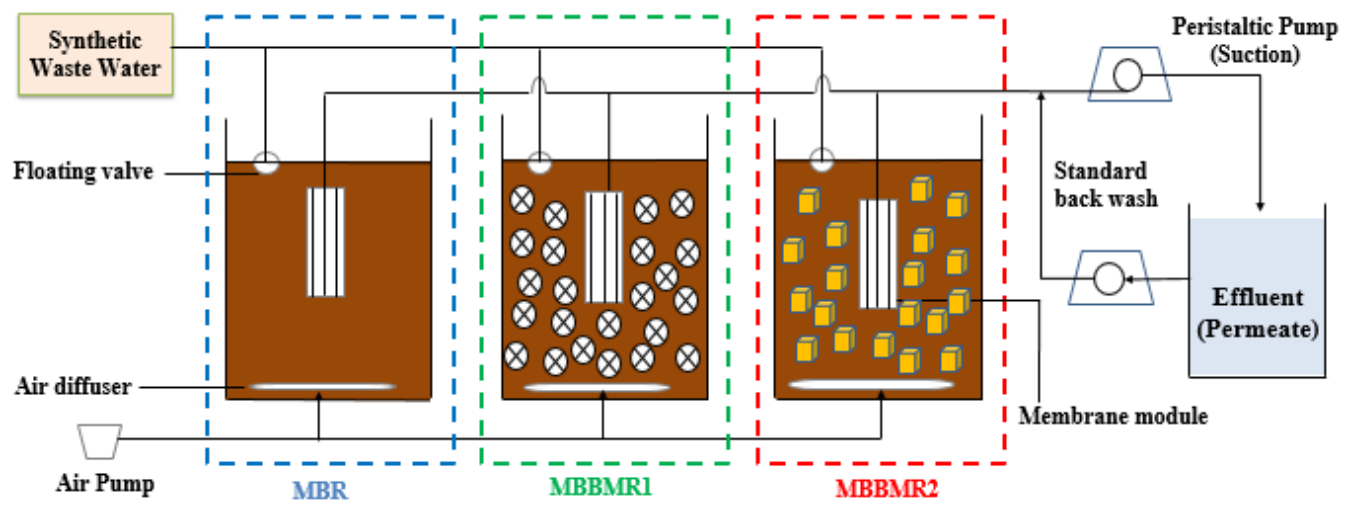

Figure 2.4 Schematic Diagram of MBR and MBBMR plants 
Table 2.3 Operational Condition of different technologies used in this research

\begin{tabular}{|c|c|c|c|c|c|c|}
\hline Type of operation & $\begin{array}{c}\text { Carrier Filling } \\
\text { Ratio } \\
(\%)\end{array}$ & $\begin{array}{c}\text { Influent and } \\
\text { Effluent Flowrate } \\
(\mathrm{mL} / \mathrm{min})\end{array}$ & $\begin{array}{c}\text { Backwash } \\
\text { flowrate } \\
(\mathrm{mL} / \mathrm{min})\end{array}$ & $\begin{array}{c}\text { Return } \\
\text { Ratio a } \\
(\%)\end{array}$ & $\begin{array}{c}\text { HRT } \\
(\mathrm{hr})\end{array}$ & $\begin{array}{c}\text { Target MLSS } \\
\text { Concentration } \\
(\mathrm{mg} / \mathrm{L})\end{array}$ \\
\hline ASP (control) & - & 13 & - & 100 & 10 & 3000 \\
\hline MBBR1 (plastic) & 20 & 13 & - & 100 & 10 & 3000 \\
\hline MBBR2 (sponge) & 20 & 13 & - & 100 & 10 & 3000 \\
\hline MBR & - & 26 & 52 & - & 5 & 8000 \\
\hline MBBMR1 (plastic) & 20 & 26 & 52 & - & 5 & 8000 \\
\hline MBBMR2 (sponge) & 20 & 26 & 52 & - & 5 & 8000 \\
\hline
\end{tabular}

a Sludge return flow rate compared to influent flowrate

\subsection{Analysis of Water Quality and Operational Parameters}

MLSS was done 5 days a week to check the growth of microorganisms. Trans membrane pressure (TMP) was monitored to check membrane fouling through super scientific data logging manometer at 1min interval and it was downloaded to PC later. COD, BOD and $\mathrm{NH}^{4+}-\mathrm{N}$ was done three, two and two times a week respectively. Water quality analysis was conducted according to Standard Method for the Examination of Water and Wastewater [12]. After completion of each operations, suspended and attached biomass of each reactor were determined. Attached biomass on the carriers was washed by distilled water and those still remain inside carriers were detached by 1 hour ultrasonication (Nexul, Model NXPC). All washed out biomass and washing water were taken into beaker and dried at $105^{\circ} \mathrm{C}$. The dry biomass was calculated as attached biomass. Waste sludge generation for each operation was determined from volume of sludge withdrawal and MLSS concentration.

\subsection{Statistical Analysis}

In order to compare the performance of different technologies on the basis of the same effluent quality, HRT of ASP and MBBRs was set two times longer than that of membrane involving technology as mentioned in section 2.3. To confirm the pre-condition of producing the same removal efficiencies, statistical analysis was conducted to test whether the removal efficiencies of different technologies were equal or not. To accomplish this, several statistical tests i.e. ANOVA (Analysis of Variance) test, Normality test (Kolmogorov-Smirnov, Shapiro-Wilks) and Kruskal Willis test [13] were performed by SPSS (Statistical package for the social sciences) software. 


\section{RESULTS AND DISCUSSION}

\subsection{Removal Efficiency Comparison and Statistical Analysis}

All the operations showed fairly good removal efficiency. $\mathrm{COD}, \mathrm{BOD}, \mathrm{NH}_{4}{ }^{+}-\mathrm{N}$ removal of all technologies were above $90 \%, 95 \%$ and $98 \%$ respectively. The removal efficiency of COD, BOD and $\mathrm{NH}_{4}{ }^{+}-\mathrm{N}$ across six operational groups are shown in Figure 3.1, 3.2 and 3.3 respectively. These graphs seem to have some differences in removal efficiencies. MBBMR1 and 2 seem slightly more stable than others. In order to check if the pre-condition (the same removal efficiencies for all the operations) was met or not, statistical analyses were conducted.

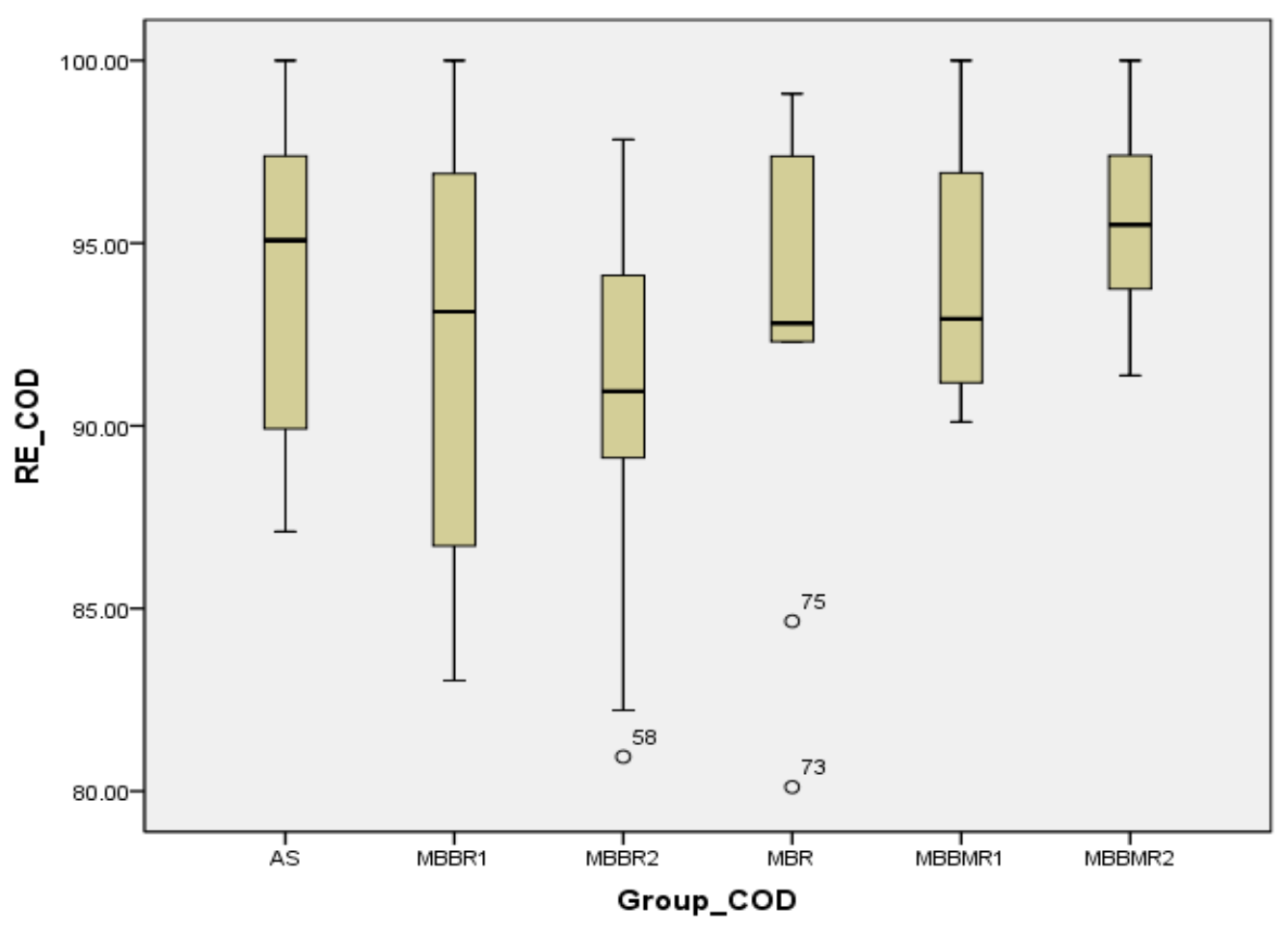

Figure 3.1 Distribution of Removal Efficiency of COD across all Operations 


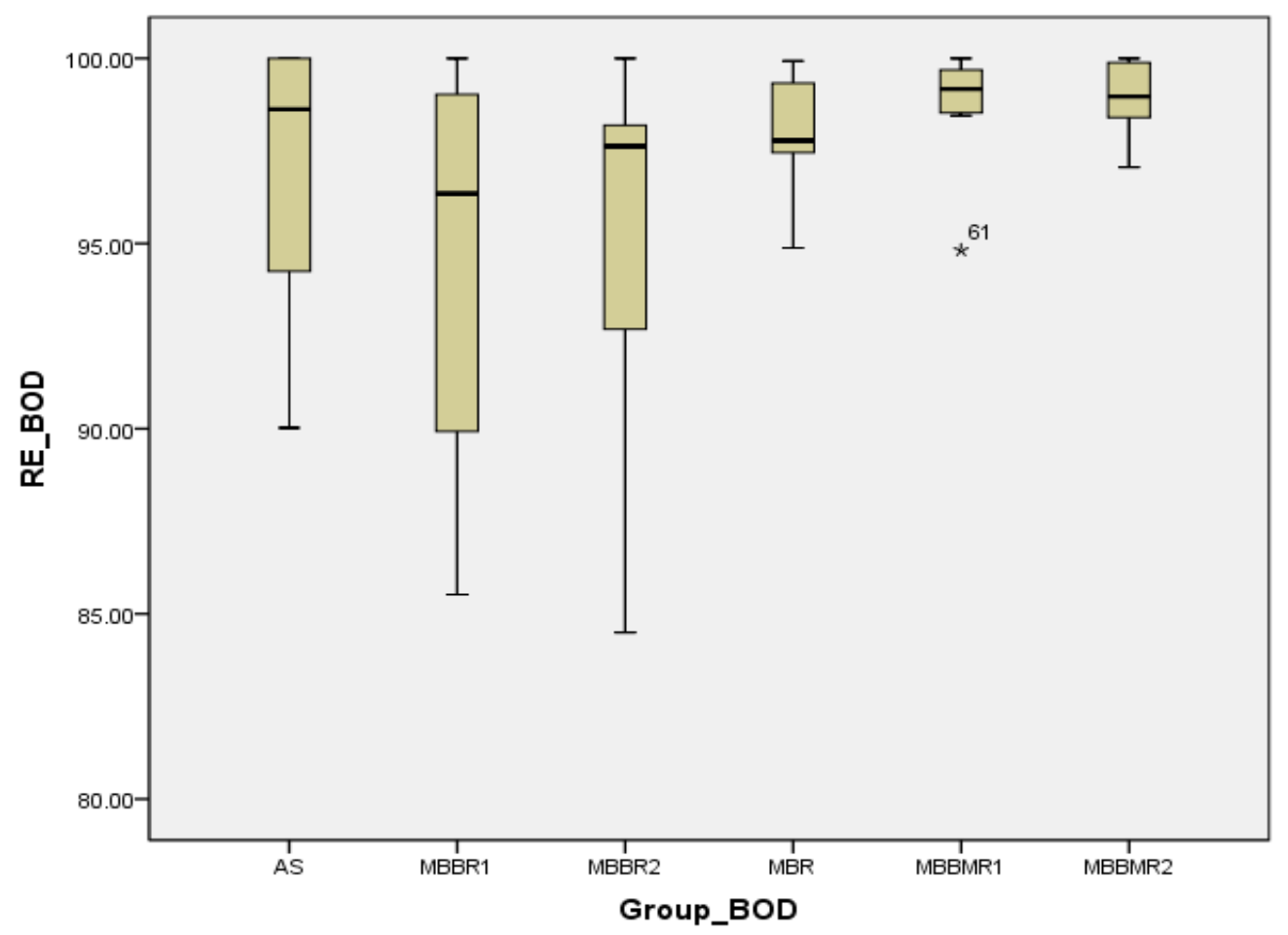

Figure 3.2 Distribution of Removal Efficiency of BOD across all Operations

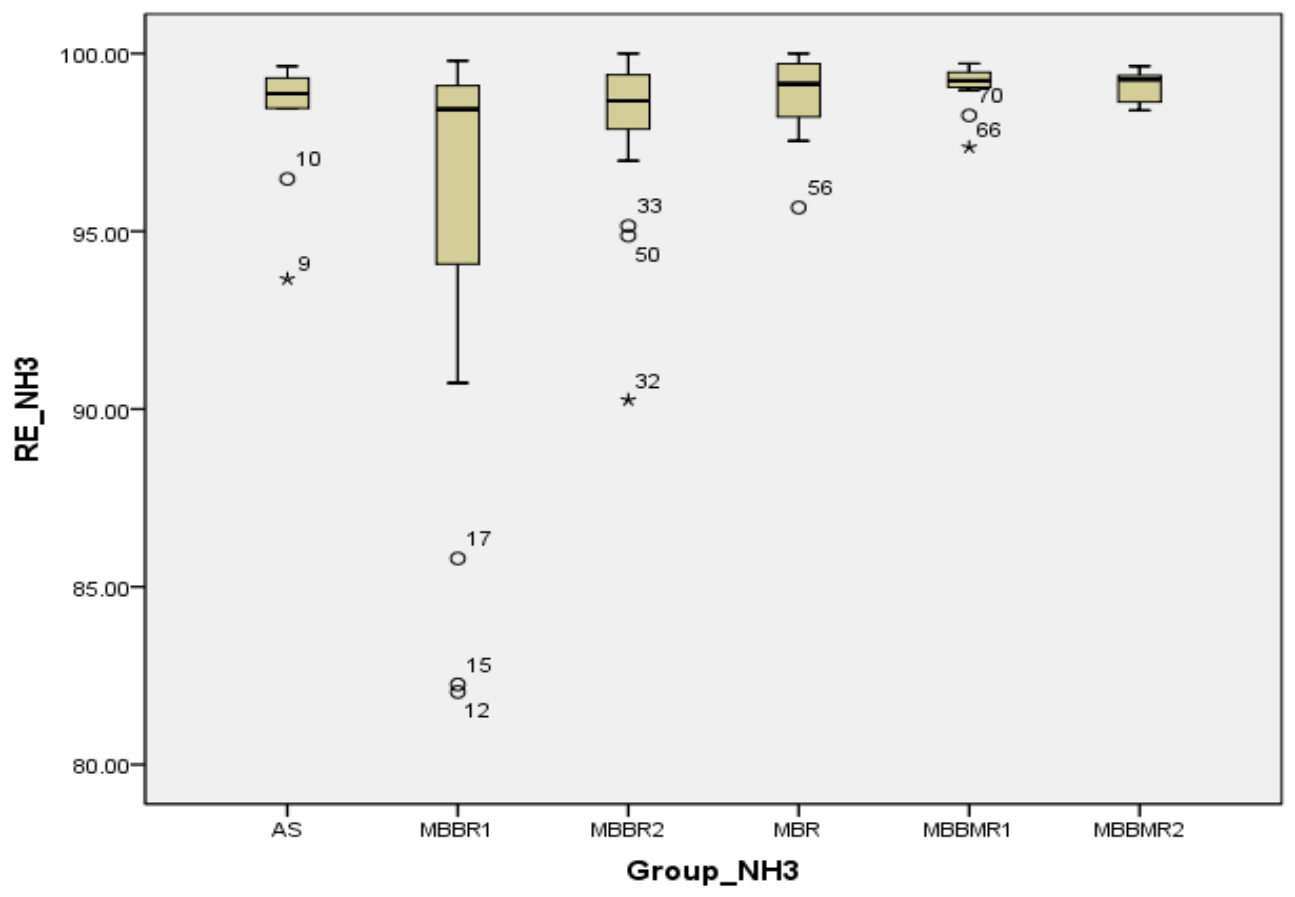

Figure 3.3 Distribution of Removal Efficiency of $\mathrm{NH}_{4}{ }^{+}-\mathrm{N}$ across all Operations 
Averages of more than two sample groups can be tested whether there is meaningful difference between groups by one way ANOVA (Analysis of variance) test. But this ANOVA test has assumptions to be applied such as, normality, homogeneity of variances of each group, independence of samples [13]. Therefore normality was tested by Kolmogorov-Smirnov and Shapiro Wilks test before applying ANOVA test. The results of normality test for $\mathrm{COD}, \mathrm{BOD}$ and $\mathrm{NH}_{4}{ }^{+} \mathrm{N}$ were shown in Table 3.1. Some of significance values in Kolmogorov-Smirnov and Shapiro-Wilks test are greater than 0.05, which mean the data do not follow normal distribution. Not all of them follow normal distribution, therefore, one-way ANOVA test cannot be applied here. Because of non-normality of data, non-parametric counter part of ANOVA, which does not require the normality assumption i.e Kruskal Wallis test was applied for testing difference between groups instead of one-way ANOVA [14].

Table 3.1 Normality Test Results

\begin{tabular}{|c|c|c|c|c|c|c|c|}
\hline \multirow{2}{*}{$\begin{array}{c}\text { Water } \\
\text { Quality } \\
\text { Parameter }\end{array}$} & Operations & \multicolumn{3}{|c|}{ Kolmogorov-Smirnov } & \multicolumn{3}{c|}{ Shapiro-Wilk } \\
\cline { 2 - 8 } & & Statistic & Df & Significance & Statistic & Df & Significance \\
\hline \multirow{5}{*}{ COD } & ASP & .190 & 12 & $.200^{*}$ & .917 & 12 & .266 \\
& MBBR1 & .132 & 29 & $.200^{*}$ & .927 & 29 & .046 \\
& MBBR2 & .113 & 25 & $.200^{*}$ & .946 & 25 & .205 \\
& MBR & .273 & 9 & .052 & .878 & 9 & .149 \\
& MBBMR1 & .208 & 14 & .103 & .907 & 14 & .141 \\
& MBBMR2 & .108 & 14 & $.200^{*}$ & .964 & 14 & .780 \\
\hline \multirow{5}{*}{ BOD } & ASP & .246 & 9 & .125 & .796 & 9 & .018 \\
& MBBR1 & .244 & 19 & .004 & .844 & 19 & .005 \\
& MBBR2 & .238 & 19 & .006 & .861 & 19 & .010 \\
& MBR & .216 & 5 & $.200^{*}$ & .936 & 5 & .638 \\
& MBBMR1 & .328 & 9 & .006 & .721 & 9 & .002 \\
& MBBMR2 & .163 & 9 & $.200^{*}$ & .917 & 9 & .371 \\
\hline \multirow{5}{*}{$\mathrm{NH}_{4}{ }^{+}-\mathrm{N}$} & ASP & .343 & 10 & .001 & .720 & 10 & .002 \\
& MBBR1 & .309 & 20 & .000 & .703 & 20 & .000 \\
& MBBR2 & .231 & 21 & .005 & .724 & 21 & .000 \\
& MBR & .273 & 7 & .125 & .844 & 7 & .108 \\
& MBBMR1 & .284 & 12 & .008 & .780 & 12 & .006 \\
& MBBMR2 & .206 & 12 & .171 & .901 & 12 & .164 \\
\hline
\end{tabular}

*: This is a lower bound of the true significance.

The results of Kruskal Wallis test were summarized in Table 3.2. P-value of COD, BOD and $\mathrm{NH}_{4}{ }^{+}-\mathrm{N}$ are all greater than 0.05 which means all the sample distributions are equal. It can be concluded that the removal efficiencies of all 6 operations have no significant difference. MBR, MBBMR1 and MBBMR2 did not have adverse effect on effluent quality in spite of short HRT. And ASP, MBBR1 and MBBR2 also showed good removal efficiencies to be equal to those of MBR, MBBMR1 and MBBMR2 because of long HRT. So, it was statistically proved that the pre-condition in this research (the same removal efficiencies for all the operations) was met. 
Table 3.2 Removal Efficiencies of COD, BOD and $\mathrm{NH}_{4}{ }^{+}-\mathrm{N}$ with Kruskal Wallis Test Results

\begin{tabular}{|c|c|c|c|c|c|c|c|c|c|}
\hline \multirow{2}{*}{ Operation name } & \multicolumn{3}{|c|}{ COD } & \multicolumn{3}{c|}{ BOD } & \multicolumn{3}{c|}{$\mathrm{NH}_{4}{ }^{+}-\mathrm{N}$} \\
\cline { 2 - 11 } & Median & Min & Max & Median & Min & Max & Median & Min & Max \\
\hline ASP & 95.1 & 87.1 & 100 & 98.6 & 90 & 100 & 98.9 & 93.7 & 99.6 \\
\hline MBBR1 & 93.1 & 83 & 100 & 96.3 & 85.5 & 100 & 98.4 & 82 & 99.8 \\
\hline MBBR2 & 90.9 & 80.9 & 97.8 & 97.6 & 84.5 & 100 & 98.7 & 90.3 & 100 \\
\hline MBR & 92.8 & 80.1 & 99 & 97.8 & 94.9 & 99.9 & 99.1 & 95.7 & 100 \\
\hline MBBMR1 & 92.9 & 90.1 & 100 & 99.2 & 94.8 & 100 & 99.2 & 97.4 & 99.7 \\
\hline MBBMR2 & 95.5 & 91.4 & 100 & 98.9 & 97.0 & 100 & 99.3 & 98.4 & 99.6 \\
\hline Kruskal-Wallis Test & \multicolumn{1}{|c|}{ P-value $=0.141>0.05$} & P-value $=0.089>0.05$ & P-value $=0.093>0.05$ \\
\hline
\end{tabular}

\subsection{Performance Evaluation}

Performance of wastewater treatment technology can be evaluated in aspect of effluent quality (removal efficiency), amount of treated water (effluent production), operational duration of membrane module (in case of membrane technology) and waste sludge generation. In this research, treatment efficiencies of all different technologies were equally good, and no significant difference was found. So, the overall performance comparison was made in aspect of effluent production, operational duration of membrane module, biomass holding capacity and waste sludge generation.

\subsubsection{Effluent production}

Effluent productions of each operation during unit of time (daily production, daily treatment capacity) are shown in Figure 3.4. Conventional technology (ASP, MBBRs) produced 18.7L of effluent per day while membrane involving technologies (MBR, MBBMRs) produced 27.2L of effluent per day (net production). Membrane involving technologies actually treated 34L of wastewater per day, however, as $20 \%$ of total production (6.8L/day) was used for standard backwash, so net production was smaller than total. Membrane involving technologies were superior to conventional ones in terms of effluent production because they can be operated at lower HRT than conventional ones while maintaining equally good effluent quality. 


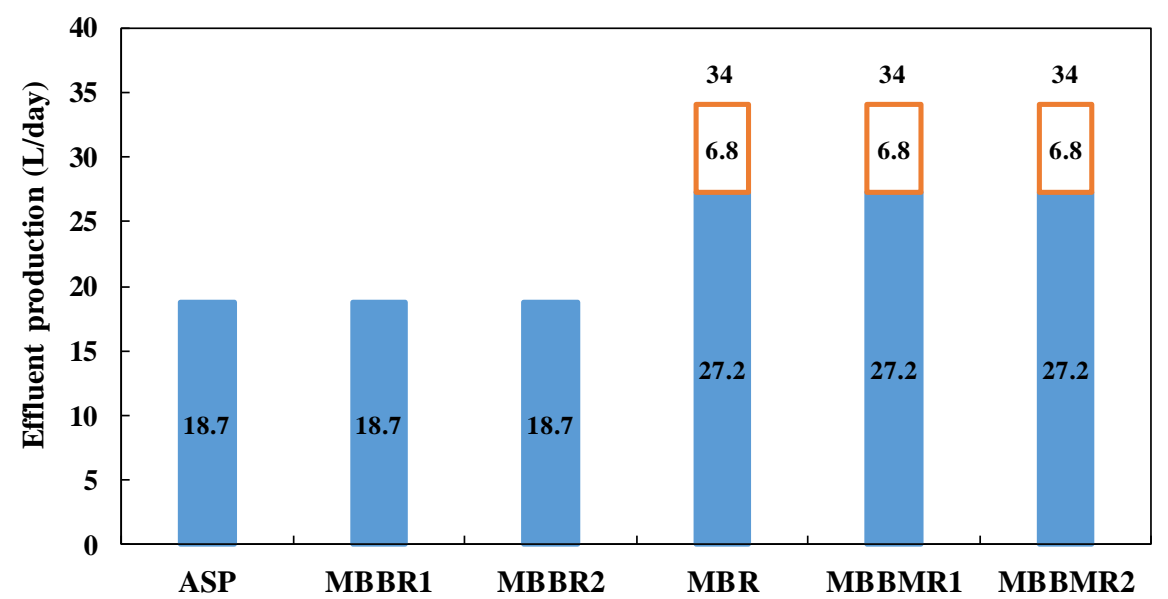

Net Effluent Production (L/day) $\square$ Consumption for Backwash (L/day)

Figure 3.4 Effluent Production of all Different Technologies

\subsubsection{Operational duration}

Per cycle operational durations of membrane involving technologies were compared as shown in Figure 3.5. Simple MBR without any carriers got fouled after 16.4 days, MBBMR1 with plastic carriers got fouled after 37.3 days and MBBMR2 with sponge carriers got fouled after 48 days. MBBMR1 worked 20.9 days longer (128\% improvement) and MBBMR2 worked 31.6 days longer (193\% improvement) than MBR. Although daily net effluent production (27.2L/day) were the same for MBR, MBBMR1 and MBBMR2, operational duration per cycle is quite different. Longer operational duration means it needs less recovery cleaning of membrane modules. Frequent recovery cleaning will cost time and chemical and further more reduce life time of membrane [15]. So in terms of operational duration, MBBMR2 was superior to the others. It was considered that the moving sponge carriers can scour the surface of membrane and detach the biofilm from the membrane better than plastic carriers. Therefore it can be suggested that hybrid MBBMR2 with sponge carrier was better technology than others. 


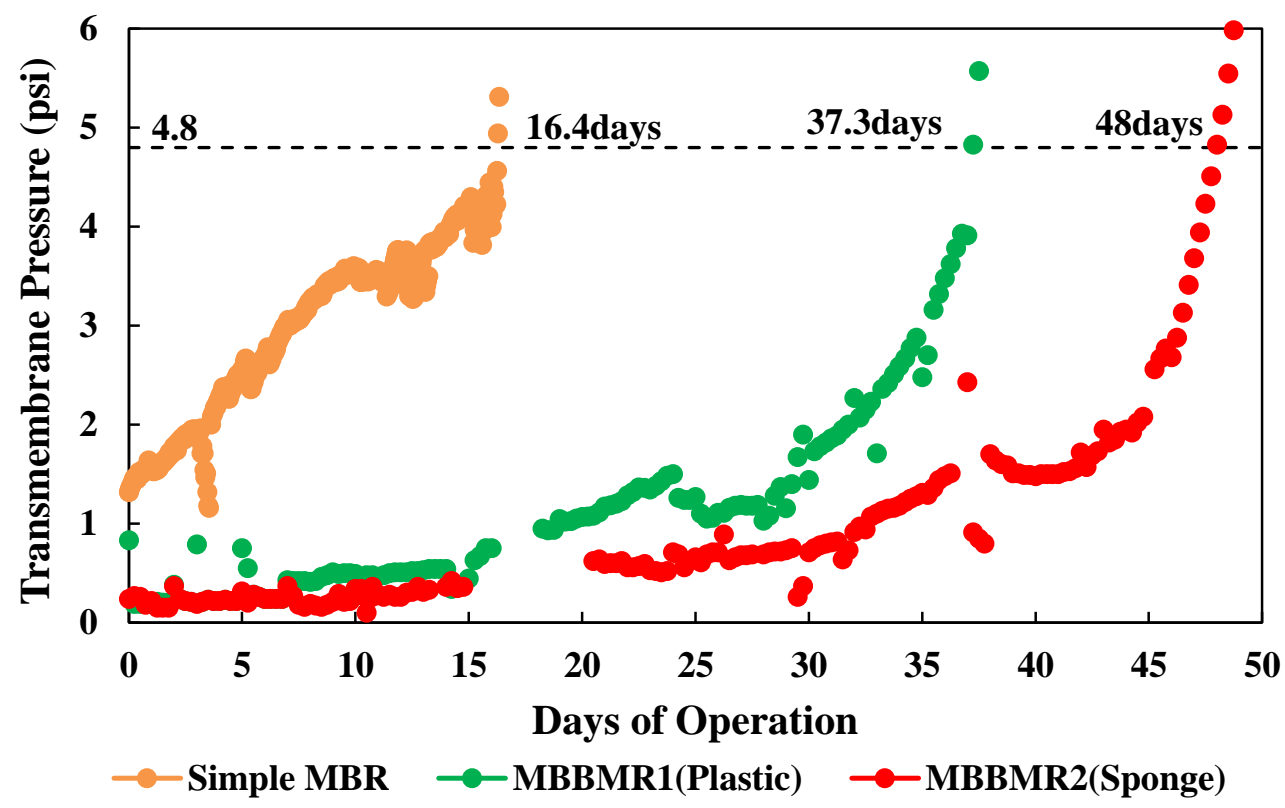

Figure 3.5 TMP Profile of Simple MBR, MBBMR1 and MBBMR2

\subsubsection{Biomass in the bioreactor and waste sludge generation}

Figure 3.6 show that suspended attached biomass of different operations. MBBR1 and MBBR2 had 25.3g and $28.7 \mathrm{~g}$ of biomass in the reactor respectively while ASP had only 18.1g. MBBMR1 and MBBMR2 had $69.8 \mathrm{~g}$ and $67.2 \mathrm{~g}$ of biomass in the reactor respectively while MBR had $63.7 \mathrm{~g}$. It was observed that membrane involving technologies had more biomass because higher MLSS was maintained as designed. And it was observed that carrier involving technologies (MBBR1, 2, MBBMR1 and 2) have more total biomass in the reactor because attached biomass was added on top of suspended one. When plastic carriers and sponge carriers were compared (MBBR1 vs MBBR2; MBBMR1 vs MBBMR2), sponge carriers had more attached biomass. It is because sponge carriers have more greater surface area inside of structure of sponge. More biomass in the reactor is beneficial since it can treat more wastewater within short time and leads longer solid retention time as well as less sludge generation. Picture of attached biomass on plastic and sponge carriers are shown in Figure 3.7. 


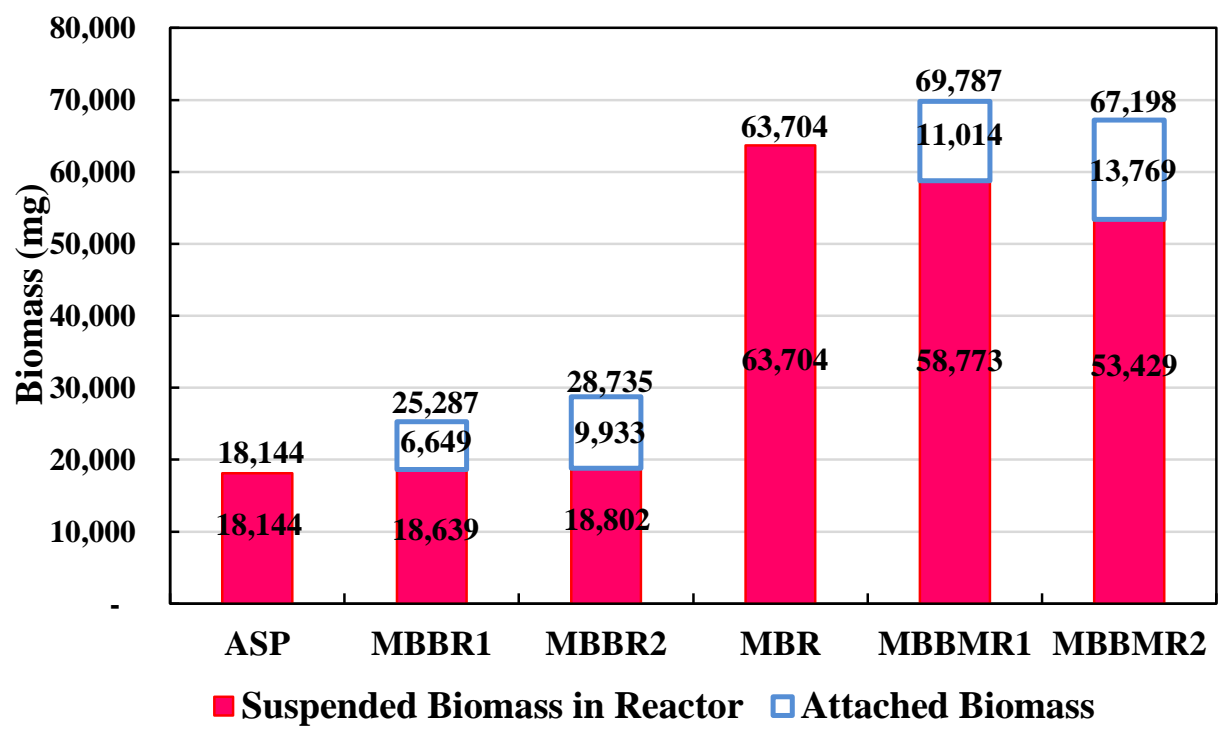

Figure 3.6 Comparison of Biomass in Different Operation

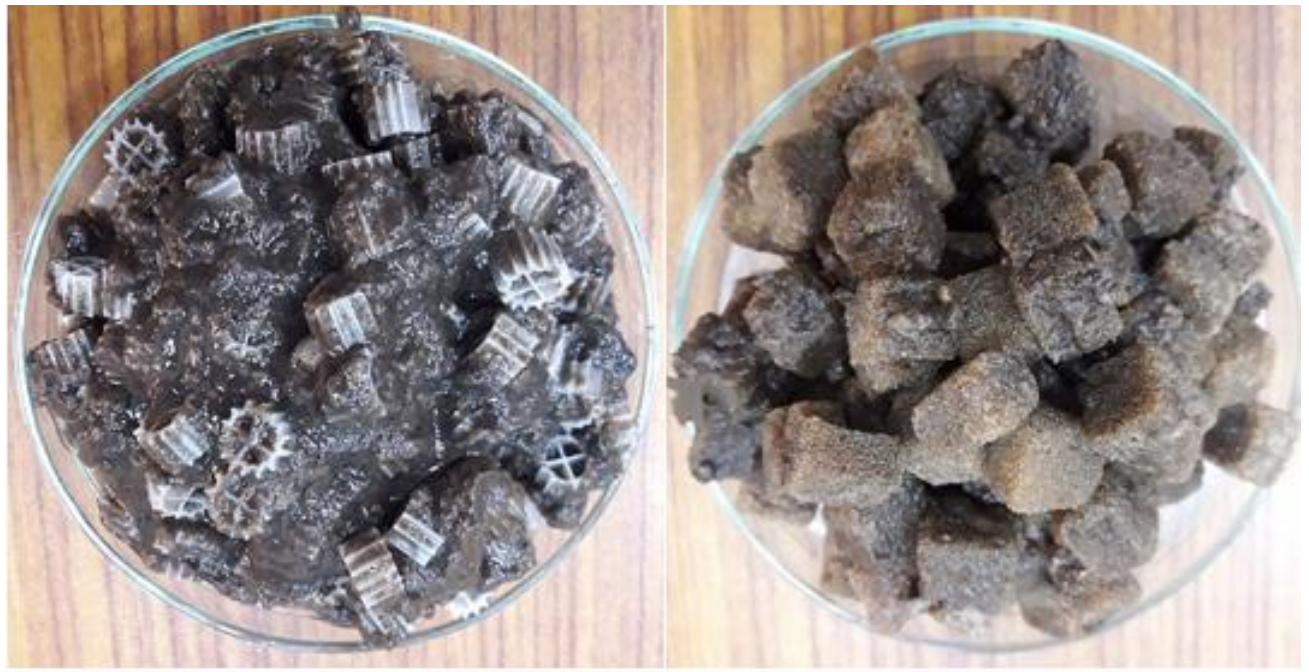

Figure 3.7 Attached Biomass on the Plastic and Sponge Carriers

After wastewater treatment, by-product in form of sludge is generated which needs additional cost to treat. Therefore a technology that generated less sludge is preferable. Waste sludge generated during the operations of different technologies were determined and shown in Figure 3.8. The amount was calculated based on the amount of withdrawal of sludge to maintain target MLSS concentration for each operation per the amount of wastewater treated during the period. Waste sludge generation of MBR, MBBMR1 and MBBMR2 were smaller than MBBR1 and MBBR2. Out of all, MBBMR2 generated the least sludge (44.2kg dry sludge $/ 10^{6} \mathrm{~L}$ treated wastewater). So, in terms of by-product generation, MBBMR 2 with sponge carrier is superior to the others. 


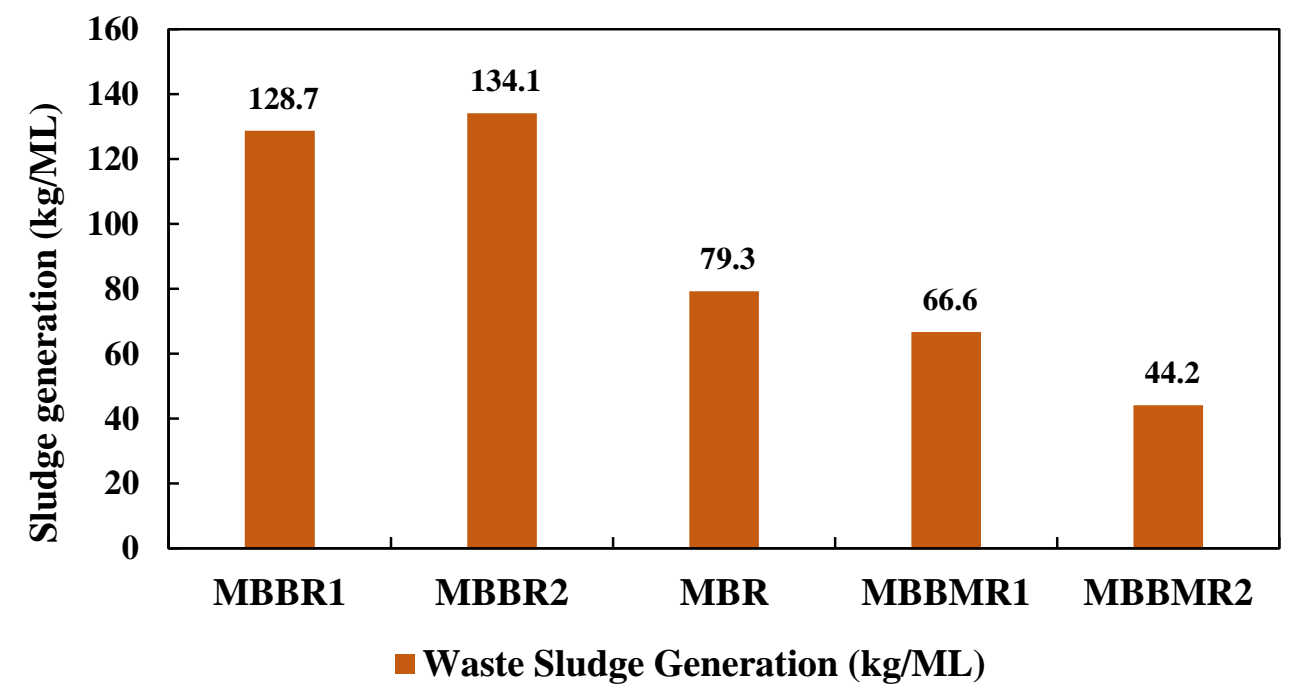

Figure 3.8 Waste Sludge Generation of Different Technologies

\section{Conclusion}

All the operations representing ASP, MBBRs, MBR, and MBBMRs showed fairly good removal efficiencies for COD, BOD, $\mathrm{NH}_{4}{ }^{+}-\mathrm{N}$ to be above $90 \%, 95 \%$ and $98 \%$ respectively. No significant difference was found in all technologies in effluent quality under the operational condition of this research and it was confirmed by statistical analysis (Kruskal Wallis Test).

Membrane involving technology (MBR, MBBMRs) can treat more wastewater than conventional ones (ASP, MBBRs) because they can be operated at high hydraulic loading, short HRT without deterioration of effluent quality. The effluent production of MBR and MBBMRs were observed greater than ASP and MBBRs.

Physical cleaning effect by sponge carriers was proven to be one of the useful options for improving MBR performance by mitigating biofouling as moving carriers physically wash biofouling layer from the membrane. Operational duration of MBBMR with sponge carrier was longer than the others and biomass holding capacity of sponge carrier also was better than plastic carrier.

It was concluded that hybridization of MBR and MBBR with sponge carrier was the best method to improve performance of wastewater treatment among the evaluated methods in this research as it had high effluent production, the longest operational duration and the least waste sludge generation, which makes it more economically viable among other technologies.

\section{Acknowledgement}

This research work was supported by Korean Peace Funds and Internal Research and Innovation Fund, FCCU. 


\section{References}

[1] Abbas, T., Majeed, A.D., (2016). Applicability of MBR Technology for Decentralized Municipal Wastewater Treatment in Iraq. Ministry of Sci. and Technol. Iraq, 28-30.

[2] Leyva-Díaz, J. C., Calderón, K., Rodríguez, F. A., González-López, J., Hontoria, E., \& Poyatos, J. M. (2013). Comparative kinetic study between moving bed biofilm reactor-membrane bioreactor and membrane bioreactor systems and their influence on organic matter and nutrients removal. Biochem. Eng. J., 77, 28-40.

[3] Karim, M. A., \& Mark, J. L. (2017). A Preliminary Comparative Analysis of MBR and CAS Wastewater Treatment Systems. Int. Water Wastewater Treat,3(2). Doi http://dx.doi.org/10.16966/2381-5299.138.

[4] Leyva-Díaz, J. C., Martín-Pascual, J., González-López, J., Hontoria, E., \& Poyatos, J. M. (2013). Effects of scale-up on a hybrid moving bed biofilm reactor-membrane bioreactor for treating urban wastewater. Chem. Eng. Sci., 104, 808-816.

[5] Diaz, J.C., Munio, M.M., Lopez, Gonzalez. J., Poyatos, M.J. (2016). Anaerobic/anoxic/oxic configuration in hybrid moving bed biofilm reactor-membrane bioreactor for nutrient removal from municipal wastewater. Ecol. Eng.,91: 449-458

[6] Shokoohi, R., Asgari, G., Foroughi, M., Hemmat, S.M. (2017) Modelling of moving bed biofilm reactor (MBBR) efficiency on hospital wastewater (HW) treatment: a comprehensive analysis on BOD and COD removal. Inter. J. Environ. Sci. Tech., 14: 841-852.

[7] Leyva-Díaz, J. C., Martín-Pascual, J., Muñío, M. M., González-López, J., Hontoria, E., \& Poyatos, J. M. (2014). Comparative kinetics of hybrid and pure moving bed reactor-membrane bioreactors. Ecol. Eng., 70, 227-234.

[8] Deng, L., Guo, W., Ngo, H. H., Zhang, X., Wang, X. C., Zhang, Q., \& Chen, R. (2016). New functional biocarriers for enhancing the performance of a hybrid moving bed biofilm reactor membrane bioreactor system. Bioresource Technol., 208, 87-93.

[9] Leyva-Díaz, J. C., González-Martínez, A., González-López, J., Muñío, M. M., \& Poyatos, J. M. (2015). Kinetic modeling and microbiological study of two-step nitrification in a membrane bioreactor and hybrid moving bed biofilm reactor membrane bioreactor for wastewater treatment. Chem. Eng. J., 259, 692-702.

[10] Rahimi, Y., Torabian, A., Mehrdadi, N., Habibi-Rezaie, M., Pezeshk, H., \& Nabi-Bidhendi, G. R. (2011). Optimizing aeration rates for minimizing membrane fouling and its effect on sludge characteristics in a moving bed membrane bioreactor. J. Hazard. Mater., 186(2-3), 1097-1102.

[11] Weerasekara, N. A., Choo, K. H., \& Lee, C. H. (2014). Hybridization of physical cleaning and quorum quenching to minimize membrane biofouling and energy consumption in a membrane bioreactor. Water Res., 67, 1-10.

[12] Standard Methods for the Examination of Water and Wastewater (2012). 22nd edition, American Public Health Association/American Water Works Association/Water Environment Federation, Washington DC, USA.

[13] Anderson, D. R., Sweeney, D. J., \& Williams, T. A. (1996). Statistics for business and economics. 6th Edition. West Publication, 28: 452-453.

[14] Statistics, L. (2013). Kruskal-Wallis H Test using SPSS. Acedido em agosto, 13, 2013. 
[15] Meng, F., Yang, F., Shi, B., \& Zhang, H. (2008). A comprehensive study on membrane fouling in submerged membrane bioreactors operated under different aeration intensities. Sep. Purif. Technol., 59(1), 91-100. 